Eds Hubert-Jean Ceccaldi, Yves Hénocque, Yasuyuki Koike, Teruhisa Komatsu, Georges Stora, Marie-Hélène Tusseau-Vuillemin, Springer

ISBN 9783319138770

http://dx.doi.org/10.1007/978-3-319-13878-7 18

http://archimer.ifremer.fr/doc/00293/40420/

(c) Springer International Publishing Switzerland 2015

\title{
From Data to End-to-End Models: 15 Years of Research to Describe the Dynamics of Exploited Marine Ecosystems in the Eastern Channel
}

\author{
Marchal Paul ${ }^{1,{ }^{*}}$, Gasche Loic ${ }^{2}$, Girardin Raphael ${ }^{1}$, Le Pape Olivier ${ }^{3}$, Huret Martin ${ }^{4}$, Mahevas \\ Stephanie $^{2}$, Travers-Trolet Morgane ${ }^{1}$, Vaz Sandrine $^{5}$
}

\footnotetext{
${ }^{1}$ Ifremer, Unité Halieutique de Manche mer du Nord, 150 quai Gambetta, BP 699, Boulogne-sur-mer Cedex, F62321, France

${ }^{2}$ Ifremer, Unité Ecologie et Modèles pour l'Halieutique, rue de l'lle d'Yeu, BP 21105, Nantes Cedex 03, F-44311, France

${ }^{3}$ AgrocampusOuest, UMR985ESE Ecologie et santé des écosystèmes, F-35042, Rennes, France

${ }^{4}$ Ifremer, Unité Sciences et Technologies Halieutiques, ZI de la Pointe du Diable, CS 10070, F-29280, Plouzané, France

${ }^{5}$ Ifremer, Unité Halieutique de Méditerranée, avenue Jean Monnet, CS 30171, F-34203, Sète, France

*: Corresponding author : Paul Marchal, email address : Paul.marchal@ifremer.fr
}

\begin{abstract}
:
Considerable research has been conducted in the past 15 years around the Eastern English Channel ecosystem. Data collected since the 1970s on the biotic and abiotic compartments have been collated and mapped out in the mid-2000. This spatially explicit information formed a sound basis to improve knowledge on, and model, the functioning and dynamics of key ecosystem compartments, with a focus on flatfish species and fisheries and their interactions with other sectors of activity (aggregate extractions, maritime traffic). The more recent ongoing works are dedicated to the integration of those processes into several complementary end-to-end ecosystem models.
\end{abstract}

Keywords : Eastern English Channel ; Flatfish ; Spatial analyses ; Ecosystem modelling

\section{Introduction}

The English Channel concentrates a rich ecosystem along with intense and diverse human activities. At the same time, the Channel is a relatively well-circumscribed geographical area, "a world within Europe", which makes it an appropriate site for investigating the complex interactions between intensive and diverse human activities and this ecosystem. 
The English Channel is first a productive ecosystem coupling high and diversified pelagic and benthic productivity. It is home to many commercial species, encompassing their spawning and nursery areas and migratory routes.

The English Channel has also, for a long time, supported the activities of many users (e.g., fishing, maritime transport, aggregate extraction, discharges, windparks, aquaculture, tourism), in a context of climate change. It is also considered one of the most intensively used sea areas in the world. Of these human pressures, fishing activity, maritime transport and aggregate extractions are probably on the top of the French and UK Governments' agenda for that area. Thus, there were in 2007 about 1,500 French fishing vessels registered in Channel harbours, employing 4,300 fishers, and generating a gross revenue of 1.4 million $€$. Maritime transport is also a major economic activity in the Channel. Coming from around the planet and leaving in the direction of Asia, Africa and America, nearly 500 ships of over 300 tons enter and leave the Channel every day, making it 1 craft every 3 minutes. Perpendicular to this traffic, 90-120 daily rotations are operated by ferries between the continent and the British Isles, transporting 17 million passengers per annum. Marine aggregate extraction sites have for many decades been exploited along the UK coasts of the Channel and more recently along the French coasts. In 2007, 5.5 Mt of marine aggregates were extracted from several tens of $\mathrm{km}^{2}$ in UK southern coastal waters and $1 \mathrm{Mt}$ from less than 10 $\mathrm{km}^{2}$ along French coasts. Recently, this activity moved further offshore to areas trawled and dredged by French fishermen. Several hundred $\mathrm{km}^{2}$ are presently prospected by French companies both in the eastern and central Channel. All these activities have, in isolation or in combination, long been recognised to be major vectors of change for the ecosystem structure and functioning, and also for related economic maritime sectors.

These multiple and diverse interactions between human activities and the pressure they exert on the marine ecosystem necessitate to manage the Eastern Channel in an integrated and cross-sectorial fashion, consistent with the EU Marine Strategy Framework Directive (MSFD) and Marine Spatial Planning (MSP).

This study presents, in a summarized fashion, the evolution of the research conducted in the past fifteen years around the Eastern Channel ecosystem, starting from data collation all the way through end-to-end ecosystem modelling, with a focus on flatfish species and fisheries, and their interactions with other sectors of activity (aggregate extractions, maritime traffic).

\section{From data collection to mapping information layers and spatial and ecological analyses}

A considerable amount of information has been collected in the Eastern English Channel (EEC) over the period 2004-2010, mainly during three successive EU Interreg-funded projects: CHARM1 (2003-2005) covering the Dover Strait, CHARM2 (2006-2008) the whole EEC, CHARM3 (2009-2012) both the Eastern and the Western parts of the English Channel. An atlas including a variety of information layers related to the EEC physical environment (e.g., temperature, salinity, bed shear stress), 
fish and benthos habitats, trophic network and fisheries was in particular produced in the course of CHARM2 (Carpentier et al. 2009). The maps produced in the atlas were based on a collation of research surveys and commercial fisheries information. The raw information was interpolated and processed through a variety of statistical methods, including kriging, GLMs (Generalized Linear Models), GAMs (Generalized Additive Models) and quantile regressions, used for habitat suitability modeling and mapping. In addition, information on the life traits and diet of a large panel of commercial fish species was processed (geomorphometrics, stomach contents and stable isotopes analyses) to characterize the EEC trophic network in a quantitative fashion. All these information processed during a ten-year period form a comprehensive and sound basis to calibrate models covering part and/or the totality of ecosystem components.

\section{From spatial analyses to modeling ecosystem compartments}

\subsection{The common sole (Solea solea) population and fishery, from ecology along the life cycle to population dynamics}

Common sole is an abundant species in the Eastern Channel and sustains important fisheries (4000-5000 tons per year). The common sole has a complex life cycle (Rochette et al., 2013); after the eggs have hatched the larvae spend several weeks drifting in open water. Survivors go on to metamorphosis into benthic fish. Juveniles of common sole spend the first two years of their life in coastal nurseries before migrating to deeper areas, where they reproduce. To investigate the drivers of common sole abundance in the Eastern Channel, an integrated approach was developed, coupling different models describing the different life stages, to estimate the different sources of mortality throughout the whole life cycle.

Young stages (larval stages and nursery habitat dependence)

An individual-based model (IBM) coupled to a hydrodynamic model was used to simulate common sole larval supply from spawning areas to coastal and estuarine nursery grounds at the population scale on a 3 decades- time series. Hydroclimate is the main driver of abundance patterns during early stages of the life cycle. As mortality $(\sim 1 / 1000$ survival) is particularly high at these stages (eggs and larvae), hydroclimate drives the year class strength of juvenile abundance, without viewable relation with the spawning biomass (Rochette et al., 2012).

\section{Integrated life cycle model accounting for various pressures}

Essential fish habitat suitability (EFHS) models and geographic information system were combined to describe nursery habitats for sole, using parameters known to influence juvenile flatfish spatial distribution (i.e. bathymetry, sediment, estuarine influence and wave exposure). Juveniles strongly depend on shallow soft bottom sheltered coastal and estuarine nursery grounds and host a large proportion of total juve- 
nile common sole, suggesting that these restricted habitats should be considered as essential habitats for sole (Rochette et al., 2010).

A hierarchical Bayesian framework was developed for modeling the life cycle of marine exploited fish with a spatial perspective. The approach combined within an integrated framework: (1) outputs of the model for larval drift and survival that provided yearly estimates of the dispersion and mortality of eggs and larvae, from spawning grounds to settlement in coastal nurseries (Rochette et al., 2012); (2) a habitat suitability model based on juvenile trawl surveys coupled with a geographic information system, to estimate juvenile densities and surface areas of suitable juvenile habitat in each nursery sector (Rochette et al., 2010); (3) a statistical catch-at-age model for the estimation of the numbers-at-age and the fishing mortality on subadults and adults. Successive modeling approaches allowed to demonstrate that juvenile mortality on nursery grounds is high ( 1/100 survival) and strongly limits the population size (Rochette et al., 2013), fishing pressure is a main source of mortality at subadults and adult stages (Rochette et al., 2013) and spatial segregation at the successive life stages (i.e. eggs/larvae, juveniles, adults) along the life cycle limits the connectivity between different subparts of the population. Perspectives include further development of the modeling framework on the common sole and applications to other fish species to disentangle the effects of multiple interacting stress factors (e.g., estuarine and coastal nursery habitat degradation, fishing pressure) on population renewal and to develop risk analysis in the context of marine spatial planning for sustainable management of fish resources.

\subsection{Exploited ecosystems}

\section{Benthic effects of aggregate extractions}

The effects of sediment dredging on benthic groups consumed by sole and plaice in the Eastern English Channel have been assessed. Benthic species were grouped according to their diet or mobility and analyses were performed at the group level. First, a BACI (Before-After Control Impact) analysis was conducted to determine whether dredging impacted benthos abundance. This approach allowed determining relationships between dredging intensity and decreases in benthic abundance, and quantifying the recovery rate of the studied benthic groups. At the group level, it was shown that impacts of dredging are maximal from 6 to 12 months after dredging, these impacts being either positive (opportunistic groups) or negative. Concerning mobility, impacts of dredging were maximal on burrowers. On the contrary, mobile species seemed to be less impacted. Carnivorous species were among the most impacted trophic groups. Detritivores seemed to be positively impacted by dredging, at least for a few months after dredging. It was not possible to link increases or decreases in abundance after dredging to a recovery time, increases in abundance being linked to strong year effects.

Spatial interactions involving fishing fleets and other sectors of activity

Discrete choice models building in a random utility function (RUMs) were developed to determine how fishing effort is allocated spatially and temporally by a selec- 
tion of French, English and Dutch fleets fishing in the Eastern English Channel. Results showed that fishers tended generally to adhere to past annual fishing practices and to the areas where they experienced high revenues, and also that French dredgers strongly interacted spatially with English vessels. Furthermore, results indicated that maritime traffic, aggregate activity and restricted areas negatively impact the choice of many of the fleets under investigation. Other spatially-explicit statistical analyses have been conducted to evaluate, separately, the impacts of aggregate extraction and maritime traffic. The effects of both aggregate extraction intensity and the proximity to dredging sites on the distribution of fishing effort were investigated, for a broad selection of French and English demersal fleets operating in the Eastern Channel (Marchal et al., submitted). The most striking result is that, neither dredging intensity, nor the proximity to the extraction site, had a major deterring effect on fishing activities. To the contrary, the fishing effort of dredgers and potters could be larger on aggregates sites than in their close neighbourhood, while the fishing effort of netters has increased substantially in the impacted area. The attraction of fishing fleets is likely due to a local and temporary concentration of target species. However, knowledge on the vulnerability and life-history characteristics of these species to aggregate extractions suggests that over-extending the licensed areas would be detrimental to them and to their related fisheries in the longer term. Maritime traffic seems to be a perturbation for the fishing activities. However, in the case of the red mullet fishery, vessels do not avoid traffic lanes when they expect high fish densities. They then may take the risk of fishing inside the traffic lanes or in areas of high marine traffic densities. An effort has then been made to validate the outcomes of fleet dynamics models by administering a survey to French fishers operating in the Eastern Channel. Although French fishers generally did not feel constrained in the amount of space they had available for fishing, some mentioned shipping lanes, aggregate extractions and competition with other fishers as constraining factors.

\section{From modeling ecosystem compartments to holistic ecosystem modeling}

Three modelling approaches patterns have been pursued concurrently to model the impact of human activities on the Eastern Channel at the scale of the ecosystem, using the models ISIS-Fish, OSMOSE and ATLANTIS. An ISIS-Fish model was developed, including two flatfish populations (sole and plaice) and three benthic groups (Gasche et al. 2013). Fish populations interact with the fishing activity in the modeled area. Several fleets are modeled with an impact on both fish and benthos, and aggregates extractions are also built in with an impact on benthos only. No positive effects of MPAs on fish populations could be evidenced, either at the scale of the eastern English Channel or at smaller scales gathering several bays on the French and English coasts. On the contrary, effects of MPAs are very important on benthic taxa. OSMOSE and ATLANTIS present a further degree of complexity compared to ISISFish, by building in trophic interactions occurring between different ecosystem components. Both models are currently being calibrated in relation to the Eastern Channel 
ecosystem. The OSMOSE model is being applied to evaluate the effects of MPAs on fish populations. The ATLANTIS model will be applied to evaluate the effects of various area-based restrictions (including MPAs, but also spatial interactions with maritime traffic) on all ecosystem compartments including fleet dynamics and economics.

\section{$5 \quad$ Conclusions and perspectives}

Both the information on and the understanding of the Eastern English Channel marine ecosystem have been advanced substantially in the past fifteen years through systematic mapping and subsequent modeling of key ecosystem compartments and related human pressures. These information and process knowledge are currently being integrated into comprehensive end-to-end ecosystem models. The next stages will be dedicated to the evaluation of ecosystem-based management strategies, building on the different modeling approaches once fully developed and calibrated, and last to the transfer of simulation outcomes to help stakeholders and support decision making in the Eastern English Channel.

\section{References}

Archambault, B., Le Pape, O., Vermard, Y., and Rivot, E. (sub.) Impacts of spatial segregation along the life cycle on the dynamics of an exploited fish population. Canadian Journal of Fisheries and aquatic Sciences.

Carpentier, A., Martin, C.S., Vaz S. (Eds) 2009. Channel Habitat Atlas for marine Resource Management, final report / Atlas des habitats des resources marines de la Manche orientale, rapport final (CHARM phase II). INTERREG 3a Programme, IFREMER, Boulogne s/mer, France, 626 pp. \& CD-rom.

Gasche, L., Mahévas, S., and Marchal, P. 2013. Supporting fisheries management by means of complex models: can we point out isles of robustness in a sea of uncertainty? PloS ONE 8(10): e77566. doi:10.1371/journal.pone.0077566.

Marchal, P., Desprez, M., Tidd, A., and Vermard, Y. (sub.). How do fishing fleets interact with aggregate extractions in a congested sea? Estuarine and Coastal Shelf Science.

Rochette, S., Rivot, E., Morin, J., Mackinson, S., Riou, P., and Le Pape, O. 2010. Effect of nursery habitat destruction on flatfish population renewal. Application to common sole (Solea solea, L.) in the Eastern Channel (Western Europe). Journal of Sea Research, 64: 34-44

Rochette, S., Huret, M., Rivot, E., and Le Pape, O. 2012. Coupling hydrodynamic and individual-based models to simulate long-term larval supply to coastal nursery areas. Fisheries Oceanography, 21: 229-242.

Rochette, S., Le Pape, O., Vigneau, J., and Rivot, E. 2013. A hierarchical Bayesian model to merge larval drift and juvenile habitat models with exploited fish population dynamics. Ecological Applications, 23: 1659-1676. 